\title{
A imaginação antropológica: conhecimento conjetural e teleologia nos escritos de Kant sobre as raças*
}

\author{
Anthropological imagination: conjectural knowledge and teleology \\ in Kant's writings on races
}

\author{
Leonardo Rennó Santos \\ leo.renno@gmail.com \\ (Universidade de Campinas, São Paulo, Brasil)
}

\begin{abstract}
Resumo: Trata-se de acompanhar a especificação do método adequado à história natural que ocorre nos três famosos ensaios de Kant sobre as raças à luz da discussão sobre as funções da faculdade de imaginação nas suas Preleções sobre Antropologia. Pretende-se com isto indicar o modo como as disciplinas de geografia física e de antropologia se articulavam no interior da Weltkenntnis em vista das investigações de Kant sobre a natureza das faculdades humanas.
\end{abstract}

Palavras-chave: imaginação; geografia física; antropologia; história natural; Weltkenntnis.

\begin{abstract}
The objective of this study is to comprehend the specification of a suitable method for Natural History as seen on Kant's famous essays on race, based on the debate regarding the faculty of imagination carried out in Lectures on Anthropology. We seek to pinpoint the way in which Physical Geography and Anthropology articulated within Weltkenntnis as seen in Kant's investigations on the nature of human faculties.
\end{abstract}

Keywords: imagination; physical geography; anthropology; natural history; Weltkenntnis

DOI: http://dx.doi.org/10.11606/issn.2318-9800.v21i2p61-78

Respondendo em 1778 ao convite do editor Johann Breitkopf para participar de uma obra coletiva que versaria sobre história natural, Kant conclui nos seguintes termos sobre o seu interesse mais imediato nesta disciplina: "a história natural não é meu campo de atuação profissional [Studium], mas apenas meu divertimento, minha intenção principal para com ela consistindo em usá-la para corrigir e ampliar o conhecimento da humanidade [Menschheit]" (Kant, 1922, p.230). Por mais modesta que seja esta autoavaliação de Kant sobre sua contribuição para o desenvolvimento da história natural, há aqui um elemento essencial do projeto kantiano que convém ser destacado: a disciplina de história natural também possui um potencial formador

* Artigo originalmente escrito como conclusão do estágio de pesquisa doutoral concedido pela FAPESP (BEPE) entre os meses de outubro de 2014 e março de 2015 na Ludwig-Maximilians-Universität München sob a tutela do Prof. Dr. Günter Zöller. 
a respeito do gênero humano ${ }^{1}$, na medida em que é capaz de lançar luz sobre os componentes da natureza humana que estão à disposição dos seres humanos para uso no mundo. Entretanto, as confusões metodológicas de que esta disciplina clássica padecia nas mãos dos eruditos convidavam, antes, a uma investigação mais detida sobre as especificidades do tratamento da diversidade natural. Consideremos, em vista dessa questão, as circunstâncias do texto kantiano que suscitou tal convite.

Pensado de início como uma introdução de "agradável utilidade” (Kant, 1912, p.429) aos temas de geografia física que seriam discutidos com os alunos durante o semestre de verão de 1775, o anúncio de Kant para essas preleções veiculou no ambiente restrito da Universidade de Albertina uma solução para a questão da diversidade de tipos humanos, sobre a qual o professor passara a considerar propriamente com a inauguração, 20 anos antes, das suas preleções sobre geografia física (cf. Kant, 2009, pp.88-97). Este pequeno texto introdutório, por sua vez, seria em pouco tempo reformulado, recebendo um formato ensaístico por ocasião de uma coletânea de ensaios editada por Engel em 1777 e que, então, terá despertado a atenção do famoso editor de Leipzig (cf. Engel, 1777).

Uma breve comparação entre estas duas versões revela que as omissões e os acréscimos não propuseram um distanciamento de interesses em relação à geografia física. Bem ao contrário, a versão final deste ensaio oferece um melhor acabamento para uma longa reflexão sobre a diversidade humana, da qual também se incumbia a primeira parte do Conhecimento do Mundo (Weltkentniss). A respeito dessa disciplina, são bastante conhecidas as dificuldades materiais em se trabalhar com a investigação geográfica de Kant (cf. Adickes, 1911). Complexidade que, por sua vez, só aumenta em razão de Kant não ter encerrado a sua discussão sobre a questão das raças com a edição deste ensaio de 1777 . Além das preleções sobre geografia física terem continuado sem interrupção até a sua aposentadoria em 1796, Kant também editou em 1785 pelo Berlinische Monatsschrift o ensaio $B B M^{2}$ e, três anos depois, pelo Teutscher Merkur, o ensaio ÜGTP, os quais gravitaram no geral ao redor do problema da diversidade racial dos seres humanos.

O que procuraremos apresentar em relação ao Conhecimento do Mundo é a recuperação de uma linha de investigação apresentada aos alunos nas preleções sobre antropologia a respeito das funções da faculdade de imaginação, com o intuito de acompanharmos o desdobramento de uma questão de método que atravessa

10 interesse no lecionamento destes saberes positivos já havia sido atestado por Kant no seguinte Anúncio da década de 1760: "Quando percebi bem no começo de meu ensino acadêmico que uma grande negligência da juventude estudantil consiste sobretudo em aprender cedo arrazoar, sem conhecimentos históricos suficientes (...), concebi o plano de fazer da História do estado atual da Terra, ou da Geografia no sentido mais lato, uma suma agradável e fácil daquilo que ela poderia preparar para uma razão prática" (Kant, 2003, p.179).

2 As abreviações das obras kantianas seguem em conformidade com a norma estabelecida pela KantForschungsstelle. 
os sucessivos esclarecimentos de Kant a respeito da disciplina clássica de história natural. Numa palavra, procuraremos interrogar esta "trilogia de trabalhos de Kant sobre a história natural da espécie humana" (Zöller, 2007, p.83) no que dirá respeito à aplicação das faculdades humanas na investigação da diversidade da natureza.

\section{VvRm.}

No primeiro ensaio sobre as raças, o eixo da argumentação foi estruturado em torno da diferenciação entre divisão natural e divisão escolar. O texto começa com a afirmação de que a diversidade natural é mais bem organizada a partir da lei buffoniana, a qual dita "que animais que produzem entre si crias férteis (a despeito da diferença de formas que eles possam ter) ainda pertencem a um e mesmo gênero físico [physichen Gattung]" (Kant, 1912, p.429). Essa lei, também chamada de "lei comum da reprodução", faz com que um grupo à primeira vista bastante diverso de animais possa ser colocado sob uma mesma rubrica, economizando assim os princípios que precisam ser invocados para a organização da diversidade da natureza.

No tocante especificamente à espécie humana, Kant mostra que o resultado desta divisão natural - por "indicar apenas uma única causa natural desta unidade do gênero natural que equivale à unidade da força procriadora que eles [os seres humanos] possuem em comum" - é a afirmação de que todos os seres humanos pertencem não só a um mesmo gênero (Gattung), como também fazem parte de uma mesma família (Familie). Algo bastante distinto da divisão escolar que "divide os animais segundo semelhanças", resultando forçosamente na admissão de "muitas criaturas locais" (Kant, 1912, p.430) e, por conseguinte, na multiplicação das causas necessárias para a explicação da diversidade animal. Kant então esclarece que, enquanto a divisão natural "fornece um sistema natural para o entendimento", a divisão escolar “fornece um sistema escolar para a memória” (idem, p.429).

Se olharmos com mais atenção para os elementos que são articulados nesta investigação oriunda da geografia física com vistas ao estabelecimento da oposição metodológica entre as divisões natural e escolar, poderemos notar que a argumentação é estruturada ao redor das faculdades de entendimento (verdadeiro responsável pela determinação das leis que organizarão a diversidade natural) e de imaginação (aqui aludida pela memória). Como, porém, a detecção do que há de específico na natureza das faculdades humanas é de incumbência da investigação antropológica, parece razoável supor que em alguma medida essa questão também seja encontrada na preleção de Kant sobre antropologia do mesmo período.

$\mathrm{Na}$ V-Anth/Fried - oferecida no semestre seguinte à preleção sobre geografia física, cujo anúncio acadêmico compôs o essencial do ensaio $V v R m$-, Kant explora a diferença metodológica entre divisão natural e escolar em vista de três tipos 
de associação de representações, quais sejam de acompanhamento (Begleitung), contiguidade (Nachbarschaft) e afinidade (Verwandschaft) (Kant, 1997, p.512). No primeiro caso, as representações a serem associadas são as de tempo, seja por sucessão ou simultaneidade, como quando, exemplifica o professor, se liga à visão da fumaça o efeito do fogo enquanto causa. Kant esclarece que, "se não existisse o acompanhamento de representações, não poderíamos ter nenhuma causa e efeito. O acompanhamento é o primeiro e o maior grau de associação" (idem, pp.51213). Já o segundo tipo diz respeito à associação de representações de espaço, que é exemplificada da seguinte maneira: "ao viajar para um lugar em que muitos eventos ocorreram, o ânimo é agitado pelas lembranças desses eventos" (idem, p.513). Kant então conclui que essas associações de representações temporais e espaciais pertencem ambas às "associações da sensibilidade". A terceira forma de associação de representações diz respeito ao modo como "as representações são aparentadas segundo a constituição", seja por semelhança (Aehnlichkeit) ou derivação (Abstammung). Kant argumenta que a afinidade por derivação associa representações a partir de efeitos em comum, "assim a afinidade de causa e efeito produz a afinidade dos efeitos”, caso exemplar do arco-íris.

Além da explicação de fenômenos meteorológicos, tal definição também se ajusta muito bem à divisão natural proposta por Kant no primeiro ensaio sobre as raças. Ao aplicar a associação de afinidade por derivação no conhecimento da diversidade animal, o investigador da natureza consegue identificar uma origem comum para seres que são, à primeira vista, tão dessemelhantes entre si quanto os fenômenos da chuva e da luz solar. Já a afinidade por semelhança ocorre, assim explica o professor, "quando colocamos tudo em determinadas classes [Classen], de modo que, quando pensamos em algo, uma outra coisa é rememorada". Segundo esta explicação da $V$-Anth/Fried, o objetivo da associação de afinidade por semelhança é apenas um, a rememoração de uma representação a partir de um conjunto de outras representações, outro modo de afirmar que a proposição de classes visa apenas à memória. Numa palavra, este agrupamento por semelhantes faz com que a divisão escolar não possua nenhum outro objetivo além da recuperação pelo entendimento do que foi anteriormente associado.

Há, ainda, uma outra especificação apresentada em $V \vee R m$ que, se por um lado, aprofunda a limitação da divisão escolar, por outro, assimila as suas rubricas para uso do entendimento. Kant observa que, uma vez estabelecida, a história da natureza (Naturgeschichte) "transformaria o atual sistema escolar de descrição da natureza [Naturbeschreibung], que é tão extenso, num sistema físico para o entendimento" (Kant, 1912, p.434n). Segundo essa afirmação, a entrada em cena do que há de específico na faculdade de entendimento possibilitaria não apenas o julgamento dos eventos naturais tal como se mostram no presente, como também, e segundo os 
mesmos princípios, de como eles ocorreram no passado e, principalmente, "da série de transformações pelas quais eles passaram para chegar ao seu estado presente em todos os lugares", isto tudo que é obliterado pela atemporalidade intrínseca à classificação nominal da descrição da natureza.

Kant não infere deste argumento que os resultados obtidos pela classificação escolar devam ser rejeitados em proveito da classificação física. Ou, ainda, que não haja utilidade alguma para tal sistematização oferecida pela Escola ${ }^{3}$. O problema real aparece em outro ponto, quando o investigador da natureza transgride a limitação da investigação empírica para se aventurar, com o auxílio da sua imaginação, na explicação das causas primeiras da natureza a partir destas observações de curto espectro. Na terceira seção de $V v R m$, Kant rejeita, dentre as conjeturas sobre as diferenças do gênero humano, aquelas que admitem diversas criações locais:

Dizer como Voltaire: Deus, que criou as renas na Lapônia para consumir o musgo destas regiões frias, também criou ali os lapões para comer estas renas, não é uma má ideia para um poeta, mas um recurso ruim para os filósofos, os quais não devem abandonar a cadeia das causas naturais, a não ser ali onde ele claramente a vê ligada à fatalidade imediata (Kant, 1912, p.440).

Neste contexto específico do conhecimento por conjeturas, a alusão de Kant à veia poética voltairiana consegue exemplificar um uso inadequado da faculdade de composição (Vermögen zu Dichten) que, ainda segundo a V-Anth/Fried, é explicada pela capacidade humana de criação de "novos conhecimentos e representações” (Kant, 1997, p.524). A rigor, embora o emprego de conjeturas seja epistemologicamente válido, e mesmo recomendável, Kant vacila neste período quanto ao papel que deve ser atribuído à faculdade de imaginação na "história natural, da qual ainda carecemos quase que inteiramente" (Kant, 1912, p.434n). Prova disso as diversas explicitações de termos que são encontradas nos registros da $V$-Anth/Fried - Da Fantasia, $A$ Força da Fantasia, Da Faculdade para Compor -, sem que as funções específicas da Einbildungskraft sejam claramente delimitadas. Quanto às associações de representações de afinidade, por exemplo, Kant afirma que elas são "uma associação do entendimento" (Kant, 1997, p.513; cf. Hepfer, 2006, pp.30-1), e é apenas por uma intromissão das associações sensíveis da fantasia (Phantasie) que o entendimento se torna absurdo, tanto "nas conversações em sociedade", como também nos debates científicos; porque, no caso da investigação da natureza, a cadeia de causas naturais corre o risco de ser rompida em proveito de uma classificação por semelhanças que pode levar à multiplicação desnecessária de criações locais.

Seja como for, Kant não parece disposto a desqualificar a própria associação

3 Kant explora este ponto no manual de antropologia de 1798 nos seguintes termos: "A memorização judiciosa não é outra coisa que memorizar uma tabela de divisão de um sistema (por exemplo, o de Lineu) em pensamentos: nela, caso se tenha esquecido algo, é possível se orientar de novo pela enumeração dos elementos que foram preservados (...)" (Kant, 2006, p.82). 
de afinidade por semelhança. Trata-se de uma habilidade natural do poder de conhecimento humano que, portanto, precisa servir para algum fim ${ }^{4}$. 0 problema aparece quando este tipo de associação é defendido como pivô da pesquisa empírica. Tomada unilateralmente, a afinidade por semelhança favorece justamente uma precipitação de conjeturas que abandonam inteiramente os limites marcados pelo fato natural. Tal é o caso, assim vê Kant, da tese poligênica sobre a origem da espécie humana.

Respondendo a esse prejuízo, e para sustentar o seu contra-argumento de que "o ser humano foi destinado para todos os climas e todas as qualidades de solo" (Kant, 1912, p.435), Kant ainda desenvolve no anúncio de 1775 dois outros conceitos-chave para a sua explicação das raças humanas, a noção de germe (Keim) e de disposição natural (natürliche Anlage). Sendo ambos empregados para a compreensão do corpo orgânico, tanto o germe quanto a disposição natural foram definidos como "fundamentos de um determinado desenvolvimento" (idem, p.434), o primeiro dizendo respeito ao desenvolvimento das partes do corpo orgânico, o segundo respondendo pelo desenvolvimento do tamanho e da relação entre as suas partes. Kant entende que ambos estes elementos devem ser tomados como implantes que a natureza teria realizado no protótipo do gênero fundamental (Urbilde der Stammgattung) (idem, p.434n). Esta tese monogênica tem a vantagem de permitir que o investigador da natureza percorra toda a série de transformações sofridas pelas criaturas sem que a assunção destes implantes rompa com a cadeia completa de causas naturais. Kant é enfático na afirmação de que "o acaso ou leis mecânicas gerais não podem produzir semelhantes acordos. Devemos, por isso, observar tais desenvolvimentos ocasionais como pré-formados [vorgebildet]" (idem, p.435).

Em termos gerais, esta teoria dos germes originários procura responder ao grande obstáculo enfrentado pela história da natureza: a escassez de fontes materiais. Dificuldade que, para Kant, fica evidente na confrontação desta "ciência delimitada" (Kant, 1912, p.443) face ao extenso sistema escolar de descrição da natureza. Além disto, este arranjo teórico também possui o benefício de minimizar os perigos inerentes ao uso de conjeturas em terreno não refutável pela própria empiria, na medida em que corta pela raiz a multiplicação desnecessária de princípios, colocando as representações da imaginação sob o crivo dos conceitos do entendimento. Segundo os próprios termos de Kant, a sua proposição conjetural tem, "ao menos, fundamento suficiente para contrapesar outras conjeturas que encontram diferenças

\footnotetext{
4 Kant resumirá alguns anos depois esta relação entre faculdade humana e finalidade da seguinte maneira: "Tudo o que se funda sobre a natureza das nossas faculdades tem de ser adequado a um fim e conforme com o seu uso legítimo; trata-se apenas de evitar um certo mal-entendido e descobrir a direção própria dessas faculdades” (Kant, 1989, A 642/B 670). Explicação crítica que, vale ressaltar, se adéqua claramente ao interesse de Kant na disciplina de história natural, tal como testemunha a supracitada carta a Breitkopf.
} 
do gênero humano tão incompatíveis que acabam admitindo preferivelmente muitas criações locais” (idem, p.440). A rigor, a força real do recurso kantiano a conjeturas na investigação da geografia física se escora na tese de que "todos os seres humanos sobre a vasta superfície terrestre pertencem a um e mesmo gênero natural" (idem, p.429), o que, por sua vez, possibilita uma explicação razoável para a diversidade de tipos humanos a partir das quatro raças que "consistentemente geram entre si crianças férteis". Para Kant, a explicitação do conceito de uma raça, por se apoiar numa lei do entendimento para regramento da vasta diversidade natural, consistiu na espinha dorsal do seu anúncio de $1775^{5}$ e era a questão central que o filósofo esperava ver discutida por especialistas após a versão ensaística de 1777.

\section{BBM.}

Esta previsão de Kant, no entanto, não poderia ter sido mais equivocada. As críticas que o ensaio recebeu consistiram, no geral, em atacar justamente o que havia de suplementar, a sua proposição conjetural, sem que o argumento principal fosse de fato considerado. Kant faz questão de destacar esta incompreensão na abertura do ensaio BBM:

Vejo, no entanto, que homens de resto argutos apenas direcionaram a sua atenção para o ajuizamento do que, há alguns anos, foi dito a respeito desta questão secundária, qual seja do emprego hipotético do princípio, não tocando senão de leve o próprio princípio, do qual tudo depende (Kant, 1923a, p.91).

À luz dessa avaliação, não surpreende que Kant tivesse concentrado no segundo ensaio todos os seus esforços para uma determinação mais precisa do "conceito de uma raça", ao mesmo tempo em que reconhecia a necessidade de algumas explicações quanto ao conhecimento por conjeturas. À primeira vista, poderíamos supor que esses esclarecimentos adicionais consistiram num ataque frontal ao emprego da faculdade de imaginação. Na quinta seção deste ensaio de 1785, Kant não poupa críticas ao seu uso na proposição de “fundamentos de explicação” (idem, p.96). É recusado, por exemplo, "qualquer influência grosseira da faculdade de imaginação em assuntos de procriação da natureza” (idem, p.97). Entretanto, uma leitura mais cautelosa revela que Kant não está criticando a própria imaginação, mas sim as

\footnotetext{
5 Sloan recupera a tese de Unold, de que um dos motivos que teriam levado Kant a propor o NEV "foi gerado pela renovação da tese poligênica de Kames" (1979, p.125), embora o comentador explique em nota que ele próprio foi "incapaz de localizar evidência direta que comprove o conhecimento de Kant deste trabalho de Kames" (idem, p.149n82). O livro de Henry Home (Lord Kames) em questão era os Sketches of the History of Man, que recebeu uma primeira tradução de Anton Ernst Klausing em 1774 (Versuche über die Geschichte des Menschen). A partir da edição do volume 25 da Akademie, pode-se tomar por assegurado que Kant conhecia em 1775 este texto de Home (cf. Kant, 1997, p.581n081), o que confirma as teses de ambos os acadêmicos. Para referência: Unold, 1886, p.19.
} 
aplicações ilegítimas de uma faculdade cujas especificidades ainda não haviam sido satisfatoriamente mapeadas.

Reflitamos por um momento sobre a abertura do segundo ensaio sobre as raças. Kant é bastante claro quanto aos materiais variados que estão à disposição do investigador da natureza. Ou seja, já não se trata mais de afirmar que haja uma escassez de recursos. Ao contrário: "Os conhecimentos que as novas viagens divulgaram atinentes às diversidades no gênero humano contribuíram até agora para estimular o entendimento na investigação deste ponto, mais do que para satisfazêlo" (Kant, 1923a, p.91). O problema se encontra, então, na confiabilidade daquilo que é relatado. Um bom exemplo desta complicação são as inúmeras informações coletadas dos relatos de viajantes, as quais ganharam comentários no decurso das preleções de Kant sobre geografia física. Que se pesem as observações, no texto editado por Rink, sobre “os gigantes Patagônia” (Kant, 1923b, p.315) ou sobre pássaros "que possuiriam uma voz articulada, dentre os quais um que, por ex., pronunciaria de modo bem claro o nome 'Jesus Cristo" (idem, pp.411-12). Tanto aqui como no segundo ensaio, o problema imediato que se enfrenta é o da imprecisão dos relatos a partir dos quais os naturalistas arriscam conjeturas: "a liberdade das hipóteses é tão ilimitada nesta obscuridade das fontes do conhecimento que todo o esforço e trabalho para refutar nesta matéria não são senão dignos de pena, visto cada um seguir a sua própria cabeça em tais casos” (Kant, 1923a, p.96). Ora, criticar, mesmo que frontalmente, a imprecisão de tais relatos vale tanto quanto descredenciar a faculdade humana que os materializa?

Não parece ser este o caso. Nesta época, Kant já possuía uma visão mais robusta do que consistiam as funções da faculdade de imaginação que, na investigação da história natural, precisam se colocar sob as rédeas do entendimento. Segundo os registros da $V$-Anth/Mron, lecionada pouco antes da edição do ensaio BBM, Kant observa que "a faculdade de imaginação é a serva de todos os outros poderes do entendimento” (Kant, 1997, p.1261). Por subalterna que seja, porém, a imaginação não deve ser por isso menosprezada. Ao contrário, Kant faz questão de enfatizar aos seus alunos a sua relevância: "ela é a mais necessária dentre todas as nossas forças [Kräften], pois, por exemplo, em relação ao entendimento, ela produz para nós uma imagem dos nossos conceitos abstratos que podem ser aplicados in concreto". Aliás, é por ser precisamente esta força indispensável para o conhecimento que, caso distanciada das ações do entendimento, a imaginação pode se tornar descomedida: "quando involuntária, a faculdade de imaginação é fantasia [Phantasie], só então sendo desenfreada e desregrada" (idem, p.1262). O exemplo que Kant oferece deste fenômeno é ilustrativo do nosso problema, as "representações espirituais" do exaltado $(\text { Schwärmer })^{6}$. Isto acontece porque a fantasia, ou a imaginação involuntária, cria

6 Ou, em BBM: “Pois, se admito um caso que seja deste tipo, é como se eu também reconhecesse 
apenas a partir das "formas" das intuições e não a partir dos "materiais" (idem, p.1261). Por isto, o professor ainda acrescenta que "a faculdade de imaginação não substitui em nós a falta de sentidos [Sinne]".

A rigor, estes comentários oriundos da investigação antropológica mostram que, uma vez respeitada a hierarquia da faculdade humana de conhecimento, a imaginação se prova essencial na organização da multiplicidade sensível. No que diz respeito à história da natureza, Kant traz para primeiro plano o papel da imaginação, explicando aos alunos que "semelhanças são facilmente encontradas, sobretudo numa vívida faculdade de imaginação, e isto vem do fato de que nosso entendimento é orientado para o gênero [Gattung] e espécies [Arten] que se baseiam na afinidade" (idem, p.1266).

Parece inegável que essa sequência de comentários extraída do semestre de inverno de 1784/85 revela, antes, um interesse real do professor na busca por uma compreensão mais aprofundada de uma faculdade tão formidável, do que uma rejeição ampla e irrestrita das suas condutas na investigação científica. Segundo esses registros da $V$-Anth/Mron, é ainda graças à intensidade da faculdade de imaginação que o entendimento consegue aplicar a lei de associação de afinidade no contexto da história natural. E é somente por uma perda de seu controle que a imaginação leva a que "os limites da razão sejam então inteiramente rompidos e a ilusão force a passagem através dessa brecha em milhares [de casos]" (Kant, 1923a, p.97). Seja como for, Kant ainda carecia de uma visão de amplo espectro sobre estas ações da imaginação. Assim, era preciso que algumas questões metodológicas fossem esclarecidas a respeito do uso de conjeturas, a fim de que a nova delimitação do campo de investigação da história natural não sofresse de aplicações inadequadas de um método em todo caso ainda controverso.

Após a identificação do problema das fontes materiais na abertura do segundo ensaio, Kant apresenta uma questão de método, essencial para a investigação da história natural. Diz ele que os conceitos precisam ser determinados previamente à interrogação da experiência a seu respeito, "pois nela é encontrado o que se precisa apenas se for previamente sabido o que se deve procurar" (Kant, 1923a, p.91). Afinal, não tendo à disposição senão os relatos de viagens, como seria possível decidir sobre as "diferentes raças humanas", se existem "espécies [Art] inteiramente diferentes de seres humanos" ou se seria o caso de supor sobre essa questão "um significado mais estreito"? A posição de Kant é clara. E nos dois artigos sobre as raças humanas. É necessário que o conceito de raça seja previamente determinado, assim como estabelecido o princípio de sua aplicação, antes de interrogar as fontes materiais disponíveis. É neste sentido que se justificam as observações finais do segundo ensaio sobre as raças, em que a tese das criações locais é novamente combatida a partir de

então uma história de fantasmas ou magia” (Kant, 1923a, p.97). 
uma explicitação de noções.

Kant argumenta sobre a grande diversidade animal que a classificação de gêneros "segundo certas semelhanças" (Kant, 1923a, p.102) não passa de um gênero nominal (Nominalgattung) produzido pelo sistema de descrição da natureza. Já algo bastante distinto é o gênero real (Realgattung), "que requer inteiramente ao menos a origem filética [Abstammung] de um único par”. No entanto, este gênero real que é afirmado pela história da natureza, embora consiga reunir sob uma mesma rubrica seres vivos à primeira vista bastante dessemelhantes, não é capaz de organizar internamente a sua própria diversidade. Donde se segue, então, a aplicação do conceito de raça, o qual é definido por Kant como consistindo na "diferença classificatória dos animais de um e mesmo filo [Stamme], na medida em que ela é infalivelmente hereditária" (idem, p.100). Segundo a avaliação kantiana, até aquele momento apenas a "diferença hereditária da cor da pele" (idem, p.93) permitia a proposição de um experimento, confirmando, ao mesmo tempo, a aplicação do princípio "que, sem isto, seria temerário e incerto" (idem, p.100).

Mas uma questão ainda resistia. Como é possível explicar de modo razoável esta própria infalibilidade hereditária? Segundo a abordagem de Kant, não há outra saída ao historiador da natureza senão recorrer a conjeturas, método que se prova essencial para o prosseguimento da pesquisa científica, ainda que incerto no tocante às suas especificidades: "antes ousar tudo em conjeturas a partir de fenômenos dados que admitir em vista deste objetivo forças elementares especiais da natureza ou predisposições criadas" (Kant, 1923a, p.96).

Em resposta a esta liberdade irrestrita de hipóteses que decorrem das fontes obscuras de conhecimento, Kant recomenda a aplicação simultânea de duas máximas escolares, a da "economia de princípios dispensáveis" (Kant, 1923a, p.97) e da conservação inalterada da espécie “em todas as alterações dos espécimes”. De acordo com a primeira máxima (cf. Kant, 1989, A 652/ B 680), não convém assumir forças particulares da natureza nem princípios inatos, visto que a diversidade dos fenômenos naturais se mostra ilimitada. Por sua vez, como a segunda máxima advoga a autoconservação da espécie, Kant entende que algo precisa ser suposto nesse caso como existindo desde o início e que possa, ao mesmo tempo, explicar a progressiva diversidade natural. E explicar de modo infalível. A conclusão extraída é a seguinte: "O que mais pode ser a causa a não ser a de eles terem sido postos nos germes do filo original, que desconhecemos, do gênero humano (...)?” (Kant, 1923a, p.98).

Para o filósofo, a teoria dos germes originários era a única teoria que, até aquele momento, se ajustava corretamente à "infalibilidade de sua hereditariedade que é confirmada nas quatro raças nomeadas através de toda experiência" (Kant, 1923a, p.101). É forçoso aceitar, porém, que ela própria não consegue justificar a razão deste implante originário, pois isto pressupõe uma intencionalidade da 
natureza, para cuja concepção esta teoria e, a rigor, o próprio campo de investigação da história natural não ofereciam em si mesmos nenhum respaldo conceitual. É por isso que, no movimento final do segundo ensaio sobre as raças, Kant afirma que "o caráter propositivo numa organização é certamente o fundamento geral a partir do qual inferimos uma preparação que foi colocada originalmente na natureza de uma criatura com esta intenção" (idem, pp.102-3). Argumento este que se encontra ao abrigo de refutações empiristas pelo fato de seu princípio de intencionalidade não ter sido inferido da própria experiência e nem postulado à revelia do que a empiria pode ensinar. Ou seja, para Kant, a sua abordagem intencional da natureza não redunda em "ilusão" ou "invenção" precisamente porque recorre de modo adequado a "certos antropomorfismos, que são necessários ao princípio regulador de que aqui se trata" (Kant, 1989, A 697/B 724). Segundo o Apêndice à Dialética Transcendental da $K r V$, este recurso metodológico é assegurado pela própria natureza da razão humana (idem, A 699/B 727) e, ao mesmo tempo, "abre à nossa razão, aplicada ao campo das experiências, perspectivas totalmente novas de ligar as coisas do mundo segundo leis teleológicas" (idem, A 687/B 715).

É digno de atenção, porém, que no segundo ensaio sobre as raças, sobretudo a partir do recurso à intencionalidade da natureza, em nenhum momento uma discussão a respeito do corpo orgânico tenha ganhado relevo, algo que vimos ocorrer no ensaio de 1775 para a compreensão do desenvolvimento destes implantes que, agora, são elucidados mediante a noção de um propósito da natureza. Será ainda preciso esperar três anos até que Kant una os pontos destes dois artigos na explicitação do recurso aos princípios teleológicos.

III. ÜGTP.

O terceiro dos ensaios que compõem os escritos kantianos sobre as raças tem seus objetivos muito bem delimitados: refutar uma crítica apresentada por Georg Forst no artigo de 1786 Noch Etwas über die Menschenrassen ${ }^{7}$ - o que, para Kant, implicou uma explicitação do recurso à teleologia na investigação científica da natureza - e apoiar as Cartas sobre a Filosofia Kantiana ${ }^{8}$, divulgação popular realizada por Reinhold do projeto crítico?.

Colocados lado a lado os três ensaios sobre as raças, é possível constatar que

7 Uma recente tradução em inglês deste texto de Forster (Something more about the Human Races 1786) pode ser encontrada em Mikkelsen, 2013, já uma reedição do original em Forster, 1969.

8 A primeira das oito cartas de Reinhold sobre a filosofia kantiana aparece no mesmo Der Teutsche Merkur em 1786 (cf. Reinhold, 2005, p.XXXVI), do qual era também co-editor desde o ano anterior e no qual tanto a crítica de Forster quanto a resposta subsequente de Kant seriam editadas.

9 Cf. as cartas de Kant de 25 de junho de 1787, em que comunica a Christian Schütz a finalização do seu novo trabalho intitulado $K p V$, e de 28 de dezembro de 1787, em que revela a Reinhold a intenção de refutar a crítica de Georg Forster: Kant, 1922, pp.489 e 513 resp. 
a originalidade da teoria defendida por Kant no último texto não recai sobre uma reavaliação do conceito de raça ${ }^{10}$. Propriamente abordadas, uma das duas inovações reais deste ensaio de 1788 é marcada pela reconsideração da variedade (Varietät) na investigação da diversidade natural, noção que já havia aparecido no texto de 1775 - "aquelas [diferenças hereditárias] que de fato frequentemente regeneram [nacharten], mas não de modo constante, são chamadas de variedade" (Kant, 1912, p.430) - e que fora deixada de lado na explicação do método de investigação da natureza no ensaio de 1785.

De acordo com o ÜGTP, a variedade deve ser entendida como "a peculiaridade hereditária que não é classificatória, porque ela não se reproduz infalivelmente" (Kant, 1923a, p.165), o que pode explicar o fato de certas características observáveis “darem ocasião à nomeação de um ou outro tipo de ser humano [Menschenschlag] (famílias e tipos étnicos)", no mesmo sentido em que já havia sido afirmado no primeiro ensaio (Kant, 1912, p.431). O que é de fato específico do texto de 1788 é a explicação da noção de variedade, tal como da de raça, a partir da teoria dos germes originários, como disposições que teriam sido implantadas no tronco original humano, a respeito das quais é lícito perguntar então, mas apenas teleologicamente, sobre semelhante propósito da natureza. No caso das disposições naturais que objetivariam a variedade, a natureza parece ter intencionado "fundar e desenvolver subsequentemente a maior multiplicidade em vista de infinitos fins diversos" (Kant, 1923a, p.166). Neste sentido, a natureza parece “impedir a fusão recíproca, porque ela é contrária aos seus fins, a saber, a multiplicidade dos caracteres”. Já sobre as disposições naturais que respondem pelo conceito de raça, Kant conjetura que a natureza parece ter quisto "fundar e desenvolver subsequentemente a aptidão para fins mais reduzidos e essenciais”, cuja intenção seria de tornar "a criatura apta para variados climas". Kant infere, então, que a concorrência destes dois tipos de implantes "parece indicar uma natureza inesgotável em novos caracteres (tanto internos quanto externos)".

Agora, algo de maior interesse para o que procuramos entender aqui é a menção de Kant à noção schaftesburiana de design no exato momento em que busca elucidar a explicação dessa produção infinita de tipos a partir de uma mesma forma. Kant nota que a originalidade de um rosto humano é marcada "por fins particulares que ele [o indivíduo] não tem em comum com outros", isto que "todo retratista é capaz de atestar quando pensa sobre sua arte”. Em seguida, ele se pergunta sobre o fundamento desta verdade que é certamente encontrada num "quadro pintado a partir da vida e corretamente executado". Em ambos os casos, o que de fato Kant

10 Kant apenas explicita em ÜGTP que "o nome raça não é impropriamente concebido enquanto peculiaridade radical que indica uma origem filética comum e que, ao mesmo tempo, permite não só tais vários caracteres hereditários constantes de um mesmo gênero animal, como também do mesmo filo" (Kant, 1923a, p.163). 
testa é uma aproximação entre um produto da arte e um da natureza, pois, a respeito do rosto humano, é o retratista quem melhor consegue detectar a originalidade do produto natural. E, no caso do quadro pintado, deve-se aceitar que a sua verdade "não é tomada da imaginação [Einbildung]", mas que conserva algo da "pura natureza".

A este respeito, há um conjunto de observações pertencentes à V-Anth/Busolt, lecionada pouco depois da edição de ÜGTP, que pode nos auxiliar na compreensão do que Kant tinha em mente ao propor semelhante aproximação. Diz ele aos alunos: "para que possa aprazer, a arte deve parecer com a natureza. Por exemplo, uma pintura é tomada como bela quando se assemelha bastante com a natureza" (Kant, 1997, p.1511). O professor não só reconhece que o agrado proporcionado pela obra de arte decorre de sua proximidade com a natureza, como também supõe que algo de essencial da natureza deve funcionar como condição de possibilidade para o belo artístico. Ora, isto é justamente o que Kant propõe com o aproveitamento da noção de design, afirmando em ÜGTP que o retrato pintado conserva algo de inalterado da natureza. Avançando na sua preleção, é ainda acrescentado que "parece existir liberdade na natureza e a arte parece possuir conformidade a fins [Gesezmässigkeit]". Este segundo comentário adiciona uma informação importante, pois supõe a existência de uma permutação de características, pela qual a natureza é capaz de espelhar a liberdade da arte e a arte a regularidade da natureza.

Se transpusermos esta questão para a compreensão da noção de variedade, parece-nos adequada a suposição de que semelhante correspondência mútua pode assumir infinitas configurações, tanto na obra de arte, quanto na obra da natureza, afirmação que parece dar sentido à seguinte definição de verdade como consistindo "numa certa proporção de uma das muitas partes do rosto em relação às outras, a fim de exprimir um caráter individual que contém um fim obscuramente representado" (Kant, 1923a, p.166). Trata-se para o retratista e, se podemos acrescentar, para o investigador da natureza em relação às singularidades intrínsecas às famílias ou tipos étnicos, de encontrarem os meios para a apreensão desta proporção no jogo da natureza. Mas como?

Há, neste sentido, um esclarecimento adicional na $V$-Anth/Busolt que pode nos ajudar a respeito de tal representação obscura de um fim:

Um gênio se diferencia do crânio [Kopf] não segundo graus de talento, mas sim segundo a proporção afortunada das forças do ânimo que são vivificadas harmonicamente pela faculdade de imaginação. Isto é uma questão de sorte [Glük] (Kant, 1997, p.1497).

Kant reconhece a capacidade do gênio de exprimir numa obra de arte uma certa proporção capturada na natureza através de suas faculdades anímicas, embora seja forçoso aceitar que a regra mesma para essa apreensão não possa ser conhecida. Ela é obscura e trata-se, antes de tudo, de um feliz acontecimento. Notemos também que 
tal compreensão do gênio depende da possibilidade de trânsito entre os elementos da natureza e os poderes anímicos, o que, de alguma maneira, é sustentado pela força da faculdade de imaginação. Ora, este trânsito também é pressuposto na investigação da natureza quando o seu historiador procura respaldo na aplicação adequada das faculdades humanas para o conhecimento da diversidade natural.

Existe, contudo, um problema ao transportarmos esta argumentação sobre o gênio artístico para o âmbito do gênio investigativo: este suporte oferecido pela originalidade radical da imaginação não implicaria a possibilidade de que o acaso, ou mesmo as criações locais, fossem novamente reintroduzidos na explicação da diversidade natural, forçando a passagem para todo o tipo de "leis inqualificáveis e de modo algum passíveis de comprovação" (Kant, 1923a, p.179)? A resposta a essa pergunta só poderia ser uma. Implicaria sim. E é por isto que acompanhamos o aproveitamento kantiano da noção de design na explicação da diversidade infinita da natureza sem que nada tenha sido apresentado em favor da imaginação. Assim como Kant também não irá recorrer diretamente a ela no ÜGTP para enfrentar de modo não menos inovador a questão do organismo.

O terceiro ensaio sobre as raças é bastante explícito a este respeito: o problema do ser organizado "pode ser pensado apenas como sistema de causas finais" (Kant, 1923a, p.179). Esta afirmação, por sua vez, se apoia numa diferenciação operada por Kant no interior da noção de natureza entendida como "suma de tudo o que existe determinado segundo leis, contendo o mundo (enquanto natureza propriamente denominada) conjuntamente com a sua causa suprema" (idem, p.159). Isto permite a circunscrição do espaço de aplicação dos dois princípios de investigação científica teórico e teleológico - tanto no âmbito da física, que não deve se ocupar da natureza senão enquanto mundo, quanto no da metafísica, que apenas a interroga enquanto causa suprema.

Como, para Kant, “o modo de esclarecimento físico-mecânico” (Kant, 1923a, p.179) não pode ser usado no tratamento físico de um ser "em que tudo se coloca reciprocamente como fim e como meio", não há outra alternativa para o historiador da natureza que não seja a de recorrer à teleologia, embora o investigador precise reconhecer que "o uso de princípios teleológicos a respeito da natureza é sempre condicionado empiricamente" (idem, p.182). É precisamente neste sentido, e contra a cadeia infinita dos seres defendida por Forster ${ }^{11}$, que a teoria kantiana dos germes originários deve ser entendida: “Quanto a mim, derivo toda organização a partir de seres orgânicos (mediante procriação) e as formas ulteriores (deste tipo de coisas naturais) segundo leis do desenvolvimento gradual a partir de disposições originais" (idem, p.179). Kant ainda acrescenta que tais desenvolvimentos "podem

11 Cf. Kant, 1923a, p.179. A referida passagem se encontra em Mikkelsen, 2013, p.155 (e, no original, em Forster, 1969, p.85). 
ser frequentemente encontrados na transplantação de plantas". Este acréscimo é importante, porque novamente defende que sua teoria, além de propor uma explicação satisfatória da organização dos seres vivos, permite ainda um experimento, algo que deve ser exigido de uma investigação teórico-empírica da natureza. Já a pergunta sobre a origem do filo "cai completamente fora dos limites de toda a física possível aos seres humanos", mesmo que o questionamento sobre a força fundamental que deve estar na base de um ser organizado esteja ainda aberto, mas então competindo apenas à metafísica enfrentá-lo.

Para solucionar essa última questão, Kant recorrerá à dedução subjetiva das faculdades humanas ${ }^{12}$, cujo uso se explica pelo motivo de que a detecção de "uma organização" (Kant, 1923a, p.181) na natureza conduz o seu investigador a supor "uma causa efetiva segundo fins", a qual, entretanto, não pode ser forjada à revelia do que "a experiência ensina” (idem, p.180). Esta causa, por sua vez, que só pode ser pensada mediante a noção de uma força fundamental, também precisa ser conhecida

segundo os seus fundamentos de determinação apenas em nós mesmos, a saber em nosso entendimento e vontade enquanto uma causa da possibilidade de certos produtos serem inteiramente arranjados segundo fins, quais sejam as obras de arte (idem, p.181).

Segundo a interpretação de Kant, a obra de arte exprime em termos evidentes "uma faculdade para produzir algo de acordo com uma ideia que é chamada de fim", embora tenha sido também necessário reconhecer que, a respeito dos seres vivos, "o conceito da faculdade de um ser capaz de agir a partir de si conforme a fins, embora sem fim e intenção que se coloque nele ou em sua causa (...) seja inteiramente fictício e vazio". Significa com isto afirmar que, por útil que seja na detecção das faculdades humanas que são solicitadas para o conhecimento do ser organizado, o entendimento e a vontade, a obra de arte não é em todo caso suficiente como modelo para o conhecimento da diversidade natural, encontrando-se, assim, a meio caminho na explicação teleológica da noção de organismo.

Uma última observação pertencente à $V$-Anth/Busolt a respeito da imaginação pode nos ajudar a esclarecer essa limitação da explicação artística no domínio da história natural. Kant nota que "a distração voluntária é um tipo de autocontrole da razão, em que interrompemos o rumor da faculdade de imaginação que é, então, colocada num estado de ordenação a fim de que obedeça ao entendimento e à razão" (Kant, 1997, p.1484). Ora, este rumor da imaginação nada mais é do que a sua ação contínua de apreender semelhanças na diferença ou diferenças na semelhança ${ }^{13}$,

12 Segundo o texto do Primeiro Prefácio da $\mathrm{KrV}$, este método é definido como "a investigação da causa de um efeito dado e, nessa medida, também algo semelhante a uma hipótese” (Kant, 1989, A XVII).

13 Além das já supracitadas, as passagens em Kant (1997) que também podem ser consultadas a 
os resultados deste seu jogo livre variando em função dos arranjos diversos que ela e as faculdades superiores de entendimento e de razão engendrarem em vista da especificidade dos produtos da arte ou da natureza.

À luz desta explicação, podemos compreender não apenas a insuficiência da obra de arte como modelo para a explicação do ser organizado, visto indicar apenas a concorrência do entendimento e da vontade no aproveitamento das representações continuamente engendradas pela força da imaginação, como também a entrada em cena necessária da faculdade superior de fins para a explicação da noção de organismo. Segundo o artigo ÜGTP, “devemos ou renunciar a toda determinação de suas causas, ou pensar em conjunto com elas um ser inteligente" (Kant, 1923a, p.182). Esta exigência metafísica de que o ser organizado seja explicado analogicamente segundo a noção de ser inteligente reafirma a finitude estrutural da razão humana, a qual havia sido apresentada logo na abertura do terceiro ensaio: “a razão não consegue alcançar sua intenção completa na metafísica, segundo seu desejo, pela via teórica da natureza (a respeito do conhecimento de Deus) e que, portanto, só lhe resta a via teleológica" (idem, p.159). O desequilíbrio quanto ao interesse da razão e sua capacidade de realizá-lo faz com que, além de a física só poder empregar fins que "podem ser conhecidos através da experiência" na sua condução da investigação do mundo, esses mesmos fins precisem ser subordinados, na metafísica, a "um fim dado e determinado a priori através da razão prática pura (na ideia do mais alto bem) que deve suprir a falha da teoria deficiente".

Trata-se, quanto ao método de investigação adequado à história natural, de uma questão de autocontrole ou, ainda, de disciplina da razão ${ }^{14}$, segundo a qual o engenho dos naturalistas precisa se orientar no conhecimento da diversidade inexaurível de formas da natureza ${ }^{15}$. Tal, aliás, foi o feito de Buffon, reconhecido por Kant no encerramento das suas preleções sobre antropologia: “Ao contrário, decidir de modo audaz [hardi], desconsiderando as ponderações do juízo, este foi o mérito creditado por seus compatriotas ao grande autor do sistema da natureza, Buffon" (Kant, 1997, p.118. Modificado).

Esse tributo final da Anth ao engenho audacioso de Buffon é suficiente para confirmar a reciprocidade que procuramos destacar entre os três ensaios sobre as

respeito das ações específicas da imaginação são: V-Anth/Collins, pp.44-7 e 76-8, V-Anth/Parow, pp.303-5, V-Anth/Fried, pp.511-4, V-Anth/Pillau, pp.751-6, V-Anth/Mensch, pp.944-8, V-Anth/ Mron, pp.1256-62, e V-Anth/Busolt, pp.1456-9.

14 De acordo com a Doutrina Transcendental do Método da $K r V$, a crítica consegue forçar "a razão pura a abandonar as suas pretensões exageradas no uso especulativo e a retirar-se para dentro dos limites do seu próprio terreno, isto é, dos princípios práticos” (Kant, 1989, A 794/B 822).

15 Segundo a interpretação de Riedel da disputa entre Kant e Forster, "Kant não crítica o naturalismo enquanto princípio de esclarecimento metodológico, mas o uso descontrolado de um método que permite transformar a ciência em metafísica, fabricando forças fundamentais materiais que não permitem ser verificadas em nenhuma experiência possível” (Riedel, 1981, p.46). 
raças e as preleções sobre antropologia em vista da investigação kantiana sobre a natureza das faculdades humanas. Contraprova de que a reflexão continuada de Kant a respeito da extensão e dos limites da imaginação garantiu, em específico, uma articulação mais do que simplesmente temática entre as disciplinas de geografia física e antropologia no interior da Weltkenntnis.

\section{Referências}

Adickes, E. (1911). Untersuchungen zu Kants physischer Geographie. Tübingen: Mohr. Engel, J. (1777). Der Philosoph für die Welt. Band II. Dyck: Leipzig.

Forster, G. (1969). Werke in vier Bänden. 2. Bd. Frankfurt am Main: Insel.

Hepfer, K. (2006). Die Form der Erkenntnis: Immanuel Kants theoretische Einbildungskraft. Freiburg: Karl Alber.

Kant, I. (1912). Vorkritische Schriften II. Bd. 2. Berlin: Georg Reimer. Wissenchaften.

(1922). Briefwechsel. Bd. 10. Berlin: Preussischen Akademie der . (1923a). Abhandlungen nach 1781. Bd. 8. Berlin: Walter de Gruyter. . (1923b). Logik, Physische Geographie, Pädagogik. Bd. 9. Berlin: Walter de Gruyter. - (1989). Crítica da Razão Pura. Tradução de A. F. Morujão e M. P. Santos. 2.ed. Lisboa: Calouste Gulbenkian.

- (1997). Vorlesungen über Anthropologie. Bd. 25. Berlin: Walter de Gruyter. - (2003). "Notícia do Prof. Immanuel Kant sobre a Organização de suas Preleções no Semestre de Inverno de 1765-1766”. In: Lógica. Tradução de G. Almeida. Rio de Janeiro: Tempo Brasileiro.

(2006). Antropologia de um Ponto de vista Pragmático. Tradução de C. Martins. São Paulo: Iluminuras.

(2007). Anthropology, History, and Education. R. Louden; G. Zöller (ed.). Cambridge: Cambridge University Press.

. (2009). Vorlesungen über Physiche Geographie (Manuskript Holstein).

Bd. 26. Berlin: Walter de Gruyter.

Mikkelsen, J. (trad. e org.). (2013). Kant and the Concept of Race: Late EighteenthCentury Writings. Albany: Suny Press.

Reinhold, K. (2005) Letters on Kantian Philosophy. K. Ameriks (ed.). Cambridge: Cambridge University Press.

Riedel, M. (1981). Historizismus und Kritizismus: Kants Streit mit G. Forster und J. G. Herder. Kant-Studien, 72, pp.41-57.

Sloan, P. (1979). Buffon, German Biology, and the Historical Interpretation of Biological Species. The British Journal for the History of Science, 12(2), pp.109-153. 
Leonardo Rennó Santos

Unold, J. (1886). Die ethnologischen und anthropographischen Anschauung bei I. Kant und J. Reinh. Forster. (PhD Diss.). Leipzig.

Zöller, G. (2007). “Editor's Introduction”. In: Kant, I. Anthropology, History, and Education. Cambridge: Cambridge University Press.

Recebido em: 23.02.2016

Aceito em: 03.11.2016 